\title{
Parotiditis e influenza: inusual asociación durante 2017, en Santa Fe, Argentina
}

\author{
Gabriela Kusznierz', Juan Manuel Rudi', Verónica Vera Garate1, Andrea Uboldi², Raquel Cociglio, \\ Juan Carlos Beltramino ${ }^{4}$, Judith Pierini', Natalia Sioli5, Gerardo Pigliacampo ${ }^{6}$, Adriana Cesoni 7 , José D Jorge ${ }^{8}$, \\ Cecilia Cantero ${ }^{9}$, Patricia Schoult ${ }^{9}$, Freyre Cecilia ${ }^{10}$, Elsa Baumesteir ${ }^{10}$, Carlos Pastor ${ }^{11}$, Gonzalo Vidal ${ }^{1}$ y Carolina Cudós ${ }^{2}$
}

Instituto Nacional de Enfermedades Respiratorias "Dr. Emilio Coni". Santa Fe, Argentina. ${ }^{2}$ Ministerio de Salud de la Provincia de Santa Fe. Santa Fe, Argentina. ${ }^{3}$ Consultorio Privado. Santo Tomé, Santa Fe, Argentina. ${ }^{4}$ Centro de Especialidades Médicas Brown. Santa Fe, Argentina. 5Hospital "J.B Iturraspe". Santa Fe, Argentina. ${ }^{6}$ Centro de Salud Gutiérrez Este. Santa Fe, Argentina. ${ }^{7}$ Centro de Salud Evita. Santa Fe, Argentina

${ }^{8}$ Hospital de Niños "Orlando Alassia". Santa Fe, Argentina. "Hospital "G. Sayago". Santa Fe, Argentina.

${ }^{10}$ Instituto Nacional de Enfermedades Infecciosas. Capital Federal, Argentina.

${ }^{11}$ Laboratorio Central de la Provincia de Santa Fe. Santa Fe, Argentina.

Fuente de Financiamiento: Ninguno.

Los autores declaran la ausencia de conflicto de intereses.

Recibido: 17 de agosto de 2018 Aceptado: 10 de junio de 2019

Correspondencia a: Gabriela Kusznierz kusznierz@yahoo.com

\section{Introducción}

L a parotiditis es una enfermedad vírica aguda caracterizada por tumefacción y dolor en una o ambas glándulas salivales -submaxilares o submentoniana-, cefalea, dolores musculares y/o fatiga ${ }^{1}$. Puede presentarse con complicaciones como pancreatitis, orqui-epididimitis, sordera y meningitis. Es causada por un miembro de la familia Paramyxoviridae, género Rubulavirus: el virus de la parotiditis. El período de incubación promedio es de 16 a 18 días, con un intervalo de 12 a 25 días.

La parotiditis puede ser causada, además, por otros agentes infecciosos como los virus influenza, parainfluenza, citomegalovirus, virus de la inmunodeficiencia humana y Staphylococcus aureus ${ }^{1-3}$.

La parotiditis viral aguda no es un síntoma común de la infección por el virus influenza. Durante la epidemia de influenza en Massachusetts en 1975-1976, se informó parotiditis en 12 pacientes $^{4}$. En 1984 en Nueva York, se aisló virus influenza $\mathrm{A}(\mathrm{H} 3 \mathrm{~N} 2)$ de cultivos víricos de niñas de 7 años con parotiditis aguda 5 . Sin embargo, durante la temporada de influenza 2014-15, se informaron más de 200 casos en 25 estados de Estados Unidos de América (E.U.A.) ${ }^{6}$.

No obstante, los estudios que muestran evidencia de infección por el virus influenza en personas con parotiditis son limitados. El presente estudio se propuso sobre la base de casos detectados de parotiditis en edad escolar por los médicos centinelas en los comienzos de la temporada de invierno 2017, y el antecedente de parotiditis asociada a la influenza en E.U.A. junto con la advertencia de la situación por parte de la Dirección de Epidemiología en la Provincia de Santa Fe.

\section{Objetivos}

Investigar la ocurrencia de infección por el virus influenza en casos de parotiditis en una población de Santa Fe, durante 2017 y analizar las características clínicas y epidemiológicas de los casos.

\section{Materiales y Métodos}

\section{Diseño del estudio}

Población. Se estudiaron pacientes con diagnóstico de parotiditis sin restricción de edad, que acudieron a la consulta desde la semana 26 a la red de médicos que forman la Unidad de Influenza Centinela en Santa Fe.

Diagnóstico de laboratorio. Se realizó el hisopado bucal para la detección de la infección por el virus parotiditis ${ }^{7}$ y el hisopado nasal para la detección de virus influenza 
A e influenza B. Cuando la muestra de hisopado nasal fue negativa para el virus influenza, la muestra de hisopado bucal también se procesó para la detección de este virus. La detección de la infección por el virus parotiditis ${ }^{8}$ y los virus infuenza se llevó a cabo mediante la reacción de polimerasa en cadena de transcripción reversa en tiempo real (sigla en inglés RT-PCR) ${ }^{9}$, de acuerdo al protocolo recomendado por el Centros para el Control y Prevención de Enfermedades (CDC), de Atlanta, E.U.A.

Los datos clínicos y epidemiológicos se recolectaron utilizando un formulario estandarizado, que incluyó datos demográficos, presentación y curso clínico, condición pre-existente, signos y síntomas y vacunación.

\section{Vigilancia de enfermedades tipo influenza en pacientes ambulatorios}

En Santa Fe, la Vigilancia de Enfermedades Tipo Influenza (ETI) se lleva a cabo mediante la estrategia de unidad centinela, conformada por un componente clínico, uno epidemiológico y uno de laboratorio ${ }^{10}$. Cada semana, los médicos informan el número total de pacientes ambulatorios atendidos por cualquier razón y el número de pacientes con ETI por grupo de edad. Los médicos centinelas realizan un muestreo de hisopados nasales para los pacientes que consultan por ETI. Se define ETI como una enfermedad respiratoria aguda con fiebre (temperatura de $38^{\circ} \mathrm{C}$ axilar o más), acompañada de mialgias y tos y/u odinofagia.

El efecto de la circulación viral sobre la morbilidad se midió a través de la evolución del indicador de proporción de ETI (\% ETI).

\section{Resultados}

Durante 2017, el primer caso de influenza A (H3N2) se detectó en la semana 18 (30 de abril). Influenza A (H3N2) circuló hasta la semana 29 (16 de julio), con $28,5 \%$. El virus influenza B circuló entre las semanas 19 y 42 , con 20,6\%. Durante la semana $26,9,6 \%$ (indicador máximo) de las visitas de los pacientes, informadas a través de la vigilancia para pacientes ambulatorios, se debieron a la ETI.

\section{Parotiditis}

Entre las semanas epidemiológicas 26 (25 de junio) y 44 (26 de octubre), se estudiaron 22 casos de parotiditis clínica. Se detectó virus influenza en 15 casos $(68,2 \%)$; $14(93 \%)$ se tipificaron como influenza A (H3N2) y 1 (7\%) influenza B. La positividad en muestras de hisopado nasal fue de $54,6 \%$ y en muestras de hisopado bucal fue de $13,6 \%$. La máxima positividad viral se detectó en la semana 27 (Figura 1).

Las muestras que resultaron positivas para el virus parotiditis fueron dos, pertenecientes una al virus salvaje y en el otro caso, a la cepa vacunal contra virus parotiditis. Influenza A también se detectó en una de estas muestras.

En la Figura 2, se muestran las notificaciones anuales de parotiditis del Departamento La Capital, en la Provincia de Santa Fe. La tasa de notificación para el año 2012 fue de 29,2/100.000 habitantes; 2013: 27,2/100.000; 2014: 25,9/100.000; 2015: 41,2/100.000; 2016: 22,6/100.000 y 2017: 48,7/100.000 habitantes. Durante el año 2017, $60 \%$ de los casos de parotiditis se notificaron entre las semanas 24 y 29.

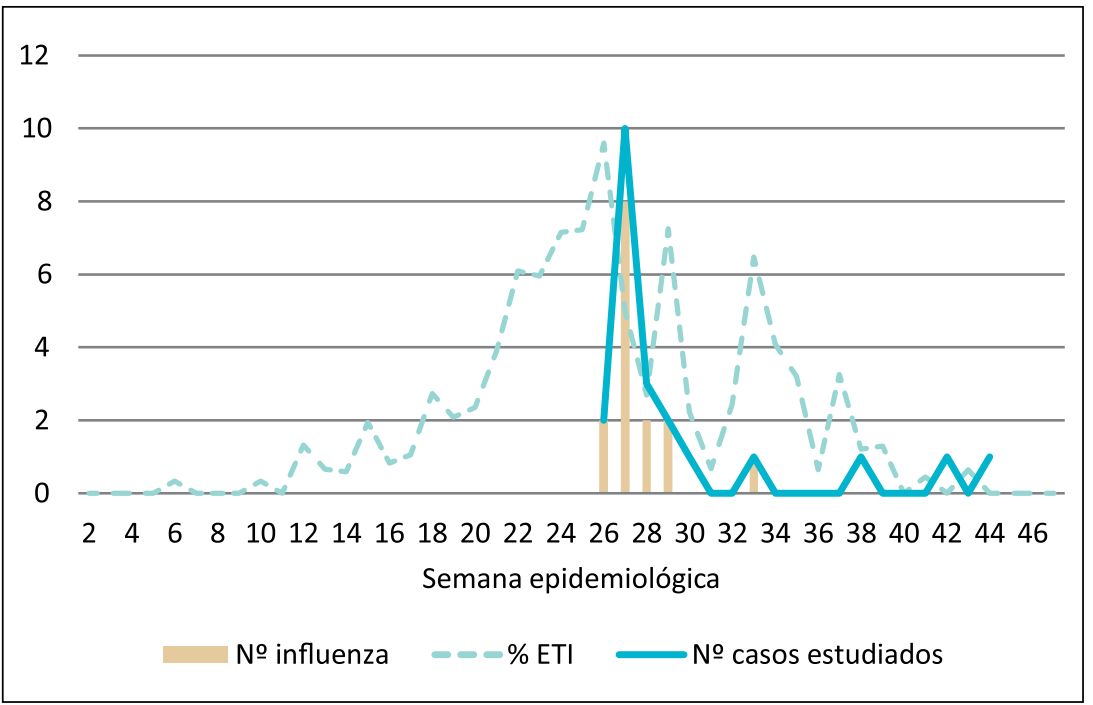

Figura 1. Casos de parotiditis debido a influenza, consultas por ETI y casos estudiados, 2017, Santa Fe, Argentina.

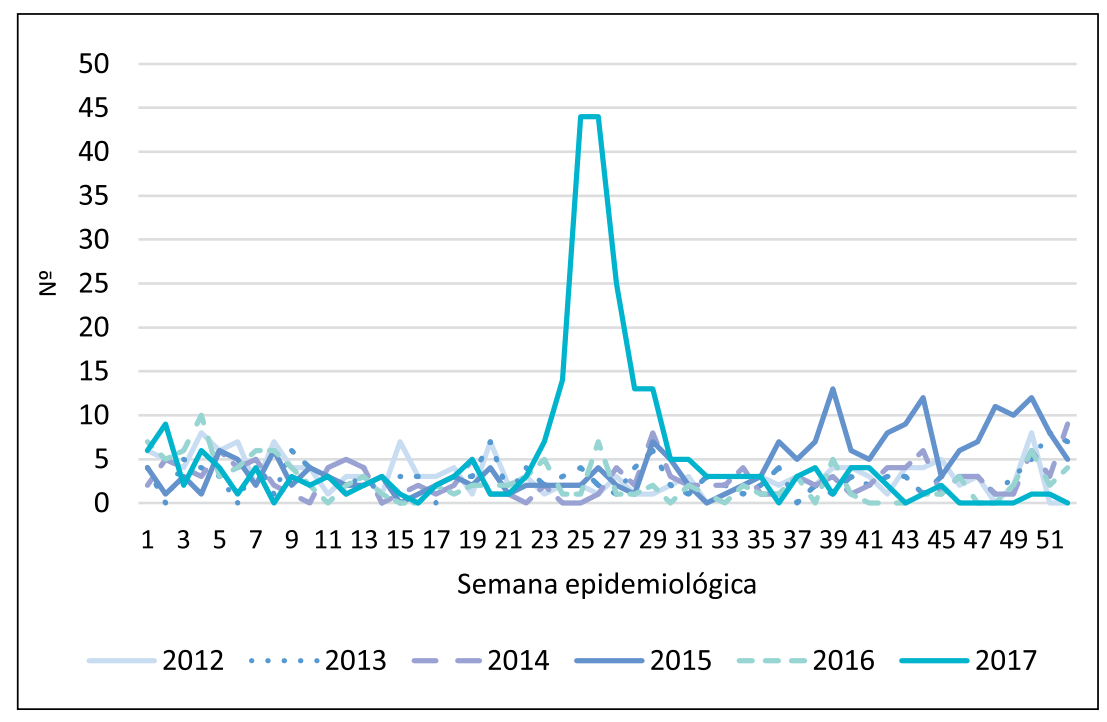

Figura 2. Notificaciones de parotiditis del Departamento La Capital, Santa Fe, Argentina, 2012-2017. 


\begin{tabular}{|clc|}
\hline \multicolumn{3}{|c|}{ Tabla 1. Virus aislados y clado, 2012-2017, Santa Fe, Argentina } \\
\hline Año & Virus & Clado \\
2012 & A/California/7/2009(H1N1)pdm09 & \\
2013 & AVictoria/361/2011(H3N2) & 3 C.1 \\
2014 & A/Texas/50/2012 (H3N2) & 3 C.1 \\
2015 & A/Switzerland/9715293/2013 & 3 C.3a \\
2016 & A/California/7/2009(H1N1)pdm09 & 3 C.2a \\
\hline 2017 & A/Hong Kong/4801/2014 & \\
\hline
\end{tabular}

\begin{tabular}{|c|c|c|c|c|c|c|}
\hline \multirow{2}{*}{$\begin{array}{l}\text { Grupo } \\
\text { de edad } \\
\text { (años) }\end{array}$} & \multicolumn{3}{|c|}{$\begin{array}{c}\text { Pacientes } \\
\text { Influenza positivo }(n=15)\end{array}$} & \multicolumn{3}{|c|}{$\begin{array}{c}\text { Pacientes } \\
\text { Influenza negativo }(n=7)\end{array}$} \\
\hline & Femenino & Masculino & $\begin{array}{l}\text { Total } \\
\text { n (\%) }\end{array}$ & Femenino & Masculino & $\begin{array}{l}\text { Total } \\
\text { n (\%) }\end{array}$ \\
\hline$<1$ & & & & 1 & & $1(14,3)$ \\
\hline $2-4$ & & & & 1 & & $1(14,3)$ \\
\hline $5-10$ & 5 & 5 & $10(67)$ & 1 & 1 & $2(28,5)$ \\
\hline $11-14$ & 3 & 2 & $5(33)$ & & 1 & $1(14,3)$ \\
\hline $25-34$ & & & & & 1 & $1(14,3)$ \\
\hline $35-44$ & & & & 1 & & $1(14,3)$ \\
\hline Total & 8 & 7 & $15(100)$ & 4 & 3 & 7 \\
\hline
\end{tabular}

\begin{tabular}{|lc|}
\hline \multicolumn{2}{|l|}{ Tabla 3. Características clínicas de pacientes, 2017, Santa } \\
Fe, Argentina & \\
\hline Características & Pacientes (n) \\
\hline Condición preexistente & \\
Asma & 1 \\
Cáncer y/o immunosupresión & 1 \\
\hline Signos y síntomas & \\
Fiebre & 10 \\
Tos & 10 \\
Dolor de garganta & 8 \\
Dolor de cabeza & 6 \\
Mialgias & 4 \\
Náuseas/vómitos & 3 \\
Dolor abdominal & 3 \\
Prostración & 3 \\
Taquipnea & 2 \\
Dolor toráxico & 2 \\
Rechazo al alimento & 2 \\
Diarrea & 1 \\
\hline Diagnóstico & \\
Parotiditis y ETI & \\
Parotiditis & 11 \\
Glándula Parótida: 1 & 4 \\
Glándula Parótida: 2 & 10 \\
GlándulaSubmaxillar 1: & 3 \\
Duración, días, media (rango) & 2 \\
Vacuna & $5(2-9)$ \\
SPR & \\
Influenza & \\
\hline
\end{tabular}

El gen de la hemaglutinina (HA) de los virus influenza detectados pertenecía al clado 3C.2a A $(\mathrm{H} 3 \mathrm{H} 2)$ que predominó durante la epidemia en Santa Fe (Tabla 1).

Entre los casos positivos, la edad promedio fue de 8,9 años (rango: 5-14 años). No se observaron diferencias estadísticamente significativas relacionadas con el sexo $(\mathrm{p}=0,24)$ (Tabla 2). Los detalles clínicos se describen en Tabla 3. La duración de la tumefacción en los casos confirmados fue en promedio de cinco días (rango: 2-9). El 74\% presentó ETI junto con parotiditis. Sólo un caso tuvo ETI después de la presentación de la parotiditis. Tenía dos dosis de vacuna contra el sarampión, parotiditis y rubéola (SPR) 74\% de los pacientes, el resto no tenía información de vacunación.

\section{Discusión}

Este es el primer informe en el Hemisferio Sur, donde se reportó parotiditis con infección confirmada por virus influenza. Nuestros resultados mostraron que el virus influenza se detectó en aproximadamente $70 \%$ de los casos con diagnóstico clínico de parotiditis. Durante el invierno de 2017, influenza A (H3N2) fue el virus predominante que circuló en Santa Fe.

Aunque en otros estudios los virus influenza fueron identificados como una causa de parotiditis, la proporción fue menor que la detectada en nuestro trabajo. En Inglaterra, se detectó influenza A (H3N2) en 15\% de los niños de 2 a 12 años con diagnóstico clínico de parotiditis, y resultado negativo para el virus parotiditis, durante el pico estacional de la influenza en 2014/2015 ${ }^{11}$. En Canadá, durante la temporada de invierno 2014-2015, 16 (13\%) fueron positivos para el virus influenza A (H3N2), 15 de los cuales fueron muestras de hisopado bucal y una muestra de hisopado nasal ${ }^{12}$. Estas diferencias pueden deberse al tipo de muestra, ya que la mejor forma para detectar influenza es mediante hisopado nasofaríngeo. El hisopado bucal no es una muestra aprobada para las pruebas de diagnóstico de influenza. Sin embargo, es similar al $13 \%$ de positividad encontrado en nuestro estudio en hisopados bucales.

En el Reino Unido, 7\% fueron positivos para el virus influenza A y dos muestras fueron positivas para el virus influenza B y resultaron ser del linaje B/Yamagata ${ }^{13}$. Nuestro estudio confirmó un caso positivo para influenza B.

De acuerdo con Chamberd C. y cols. ${ }^{12}$, también observamos un pico de positividad en niños de 5-10 años. En Canadá, el virus influenza se detectó en todos los grupos de edad (rango de edad: 4-70 años) y con mayor frecuencia en varones. En nuestro estudio no observamos diferencias en relación al sexo.

En los últimos cinco años (2012-2016), las tasas pro- 
vinciales de incidencia han oscilado entre 22,6/100.000 habitantes y 29,2/100.000 anuales, excepto en el año 2015, en que fue 41/100.000. Este aumento se produjo durante la temporada de primavera, cuando prácticamente no había circulación del virus influenza, por lo que este aumento posiblemente esté asociado con el virus parotiditis. Por el contrario, en 2017 la tasa aumentó a 48,7/100.000. Este aumento se detectó notablemente en las semanas 24 a 27, coincidiendo con la circulación máxima del virus influenza A (H3N2).

Algunas interrogantes quedan por resolver. ¿Por qué durante 2017 se observó el incremento de casos de parotiditis? En los últimos cinco años, virus A (H3N2) pertenecientes a los clados 3C.1 y 3C.3a. se distribuyeron en 2013, 2014 y 2015. Por el contrario, en 2017 los virus influenza fueron del clado 3C.2a, en consonancia con los hallazgos informados en otras publicaciones ${ }^{11-13}$. La pregunta es si las cepas del virus influenza 3C.2a A (H3N2) tienen una afinidad tisular inusual (glándulas salivales) en comparación con otros virus influenza A (H3N2).

Los síntomas clínicos de los casos fueron leves, con un promedio de la tumefacción de cinco días y sin complicaciones. Aunque la mayoría de los casos de parotiditis ocurrieron simultáneamente con una ETI, 26\% no presentó síntomas respiratorios.

Con base en estos hallazgos, los médicos deben considerar al virus influenza como una posible causa de parotiditis aguda. Es necesario implementar una vigilancia sistemática de las parotiditis asociadas con la influenza y el diagnóstico diferencial durante los períodos de circulación del virus influenza, incluso en ausencia de síntomas respiratorios.

Una limitación del estudio es que no se han investigado otros virus respiratorios en el hisopado nasal, de manera de analizar si es posible la co-detección con otros virus respiratorios. Por otra parte, las causas de $30 \%$ de los casos sin diagnóstico etiológico, pueden estar ligadas a la calidad de la muestra, la sensibilidad del método, o bien, a otros patógenos respiratorios virales como causante de parotiditis.

Es importante conocer la etiología viral de la parotiditis aguda, ya sea el virus parotiditis o el virus influenza, ya que la respuesta de salud pública frente a los brotes podría ser diferente dependiendo de si se tratara de uno u otro virus.

Agradecimientos: Los autores agradecen a los miembros del personal de la Dirección de Epidemiología de la Provincia de Santa Fe.

\section{Resumen}

Introducción: La parotiditis es una enfermedad vírica aguda caracterizada por tumefacción y dolor en una o ambas glándulas salivales, submaxilar o submentoniana, fiebre, dolor de cabeza, dolor muscular y/o fatiga. Objetivos. Investigar la ocurrencia de infección por el virus influenza en casos de parotiditis en una población de Santa Fe, durante 2017 y analizar las características clínicas y epidemiológicas de los casos. Materiales y Métodos: Se estudiaron pacientes con diagnóstico de parotiditis, que acudieron a la consulta desde la semana 26 en la red de médicos que forman la Unidad Centinela de Influenza en Santa Fe. Resultados: Entre las semanas epidemiológicas 26 y 44, se incluyeron 22 casos de parotiditis clínica. E1 virus influenza se detectó en $68,2 \%$, influenza A (H3N2) 93\% e influenza B 7\%. Los síntomas clínicos de los casos fueron leves, con una tumefacción de cinco días y sin complicaciones. El $74 \%$ presentó una enfermedad tipo influenza en conjunto con la parotiditis. Conclusiones: Este estudio evidencia que niños que presentaban parotiditis tenían una infección por el virus de la influenza A (H3N2). Es necesario implementar una vigilancia sistemática de las parotiditis asociadas con influenza y el diagnóstico diferencial, incluso en ausencia de síntomas respiratorios.

\section{Referencias bibliográficas}

1.- Litman N, Baum S G. Mumps virus. In: Mandell GL, Bennet JE, Dolin R, editors. Principle and Practice of Infectious Diseases. 7th ed. Philadelphia: Churchill Livingstone 2010:2210-6.

2.- Barrabeig I, Costa J, Rovira A, Marcos A, Isanta R, López R, et al. Viral atiology of mumps-like illnesses in suspected mumps cases reported in Catalonia, Spain. Hum Vaccin Immunother 2015; 11 (1): 282-7. doi: $10.4161 /$ hv.36165.

3.- Kang H J, Kim S H, Chung J K, Lee S W, Choi $\mathrm{S} \mathrm{B}$, Eom H E, et al. Viral etiology of sporadic cases of parotitis among children in Korea during 2013-2014. J Med Virol 2018; 90 (1): 61-6. doi: 10.1002/jmv.24935.

4.- Brill S, Gilfillan R. Acute parotitis associated with influenza type A: A report of twelve cases. N Engl J Med 1977; 296 (24): 1391-2. doi: 10.1056/NEJM197706162962408.

5.- Krilov L, Swenson. Acute parotiditis associated with influenza A infection. J Infect Dis 1985; 152 (4): 853. PMID: 4045240.

6.- Rolfes M, Millman A, Talley P, Elbadawi L, Kramer N, Blanton L et al. Influenza-associated parotitis-novel occurrence during the 20142015 United States influenza season, Open Forum Infectious Diseases, Volume 2, Issue suppl_1, 1 December 2015, 542, https://doi. org/10.1093/ofid/ofv133.417.

7.- Mumps specimen colletion, storage, and shipment. https://www.cdc.gov/mumps/lab/ specimen-collect.html. (Accedido: 5 de enero de 2018).

8.- Rota J S, Rosen J B, Doll M K, McNall R J, McGrew M, Williams N, et al. Comparison of the sensitivity of laboratory diagnostic methods from a well-characterized outbreak of mumps in New York City in 2009. Clin Vaccine Immunol 2013; 20 (3): 391-6. doi: 10.1128/ CVI.00660-12.

9.- Centers for Disease Control and Prevention (CDC). CDC realtime RTPCR (rRTPCR) 
protocol for detection and characterization of influenza A (H1N1). Available at http://www. who.int/csr/resources/publications/swineflu/ CDCrealtimeRTPCR protocol_20090428.pdf (Accedido el 3 de noviembre de 2009).

10.- Kusznierz G, Cociglio R, Beltramino J, Pierini J, D'Jorge J, Gómez A, et al. Monitoring of activity of influenza in Santa Fe, Argentina, 2005-2010. Rev Chilena Infectol 2014;31 (2): http://dx.doi.org/10.4067/S071610182014000200003.

11.- Thompson C I, Ellis J, Galiano M, Ramsay M, Brown K, Zambon M.
Detection of influenza A(H3N2) virus in children with suspected mumps during Winter 2014/15 in England. Euro Surveill 2015; 20 (31): 1-6. doi: 10.2807/1560-7917. ES2015.20.31.21203.

12.- Chambers C, Skowronski D M, Sabaiduc S, Murti M, Gustafson R, Pollock S, et al. Detection of influenza A (H3N2) clade 3C.2a. viruses in patients with suspected mumps in British Columbia, Canadá, during the 2014/15 influenza season. Euro Surveill 2015; 20 (36): 1-3. doi: 10.2807/1560-7917. ES.2015.20.36.30015.
13.- Shepherd S J, MacLean A R, Aitken, Gunson $\mathrm{R} N$. Letter to the Editor: There is a need to consider all respiratory viruses in suspected mumps cases. Euro Surveill 2015; 20 (33): pii $=21210$. doi: $10.2807 / 1560-7917$. es2015.20.33.21210.

14.- Centers for Disease Control and Prevention (CDC). CDC realtime RTPCR (rRTPCR) protocol for detection and characterization of influenza A (H1N1). Available at http://www. who.int/csr/resources/publications/swineflu/ CDCrealtimeRTPCR protocol_20090428.pdf (Accedido el 3 de noviembre de 2009). 